\title{
The American Public's Energy Choice
}

\section{Citation}

Konisky, David and Stephen D. Ansolabehere. 2012. The American public's energy choice. Daedalus 141(2): 61-71.

\section{Published Version}

doi:10.1162/DAED_a_00146

\section{Permanent link}

http://nrs.harvard.edu/urn-3:HUL.InstRepos:9738559

\section{Terms of Use}

This article was downloaded from Harvard University's DASH repository, and is made available under the terms and conditions applicable to Other Posted Material, as set forth at http:// nrs.harvard.edu/urn-3:HUL.InstRepos:dash.current.terms-of-use\#LAA

\section{Share Your Story}

The Harvard community has made this article openly available.

Please share how this access benefits you. Submit a story.

Accessibility 


\title{
The American Public's Energy Choice
}

\author{
Stephen Ansolabehere \& David M. Konisky
}

Abstract: Public opinion about energy can be understood in a unified framework. First, people evaluate key attributes of energy sources, particularly a fuel's cost and environmental harms. Americans, for example, view coal as relatively inexpensive but harmful, natural gas as less harmful but more expensive, and wind as inexpensive and not harmful. Second, people place different weights on the economic and environmental attributes associated with energy production, which helps explain why some fuels are more popular than others. Americans' attitudes toward energy are driven more by beliefs about environmental harms than by perceived economic costs. In addition, attitudes about energy sources are largely unrelated to views about global warming. These findings suggest that a politically palatable way to reduce greenhouse gas emissions is through regulation of traditional pollutants associated with fossil fuels, rather than a wholly new carbon policy.

STEPHEN ANSOLABEHERE, a Fellow of the American Academy since 2007, is Professor of Government at Harvard University.

DAVID M. KONISKY is an Assistant Professor at the Georgetown Public Policy Institute.

( *See endnotes for complete contributor biographies.)

\begin{abstract}
A gas, or uranium used to generate nearly all the electricity in the United States. Nor do they see, smell, or feel those fuels when they use electricity. In that respect, electricity consumption differs fundamentally from most other consumption goods, including our main transportation fuel, gasoline. Nonetheless, Americans have definite opinions about the best way to generate electricity because the fuels used have immediate effects on their electricity bills, as well as on economic growth, national security, and the local and global environments. Americans want less reliance on coal and oil; they want expanded use of wind and solar power; they want to continue and even expand use of natural gas; and they are deeply torn about nuclear power. ${ }^{1}$

A basic goal of public opinion research on energy is to understand how Americans view their energy choices. Are they content with the existing ways that we generate electricity, or do they want to change significantly the fuels that power the country? If the latter, what drives that preference? How important a factor is global warming, or security, or affordability? The importance of energy as a truly
\end{abstract}

(C) 2012 by Stephen Ansolabehere \& David M. Konisky 
The public policy matter has never been

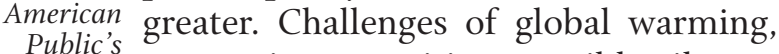
Public's
Energy

Choice city, and attendant questions of national security have pushed energy production high on the national policy agenda. In many respects, the environmental movement and public backlash over oil prices in the 1970s were only preludes to the challenges we face today.

Little is known about public attitudes toward electricity generation in general and about the fuels used in particular. Perhaps because of the tumultuous politics surrounding nuclear power and oil prices in the 1970s, there has been much public opinion and psychological research about nuclear power, especially questions of risk, and some research on oil, especially attitudes about gasoline prices and energy companies. There has been almost no research on coal and natural gas, even though those two fuels together account for approximately 70 percent of electricity generation in the United States. ${ }^{2}$ And almost no research compares energy sources directly or examines why people prefer one source over another.

The history of nuclear power makes it painfully clear how important public attitudes are to the development of energy policy and to the deployment of any method of generating electricity on a large scale. Nuclear power promised to become a great new energy source for the United States and Europe at the beginning of the 1970s. The United States had invested heavily in this new technology over the previous decade, and numerous plants were planned or under construction. However, rising fears of safety, exacerbated to some degree by Cold War fears of nuclear attack, led to public opposition and protests against siting several prominent facilities. The accident at Three Mile Island legitimated those protests and triggered a three-decade-long "nuclear winter" for the industry, as the development of new facilities came to a virtual standstill. At this time, the National Science Foundation (NSF) also began to include nuclear power as one of its key indicators of public opinion toward engineering and science. By the 1990s, however, attention to the issue had faded. Public attitudes were firmly against building new nuclear power plants, and the numbers had not moved in two decades. NSF stopped asking the public about nuclear power around 2000.

Social scientists today face the task of understanding energy choices and public opinion in a more systematic way because of the twin challenges of economic development and global warming. The prospect of global warming has transformed the debate over energy in American society. How we generate and use electricity and transportation fuel had been viewed as a specific sector of our economy, albeit an important one. A rising threat of global warming has shifted the debate from one that concerns a specific sector to one that touches on most aspects of contemporary society and economy. Further, advances in technology for energy use and consumption will be essential to the transition away from fossil fuels, and that realization has created a strong push in the United States and elsewhere to be in the forefront of the next high-tech boom, this one focused on energy. Global warming and energy innovation have put energy back onto the national political agenda - and in a much broader way than either nuclear risks or gasoline price spikes ever did. What and how the public thinks about energy choices, then, will be critical in making legislative and other policy decisions about energy use.

One troubling finding that has emerged from contemporary survey research is the absence of a connection between global warming and energy use in public opin- 
ion. Those willing to pay more on their electricity bills to solve global warming, or who say they are very concerned about global warming, express only slightly higher support for expansion of nuclear power or contraction of coal power-two changes in the U.S. energy portfolio thought to be essential to reduce greenhouse gas emissions from the electricity sector. Even if Americans were to become more concerned about global warming, it is unclear today whether those concerns would translate into support for a realignment of U.S. energy policy. Conventional environmental problems, on the other hand, strongly influence public attitudes about which fuels the United States should use. Accordingly, public policies that reduce conventional pollutants would likely have public support and could be devised so as to reduce use of fuels that emit disproportionate amounts of greenhouse gases.

$\mathrm{Pu}$ Plic opinion about energy can be understood in a common, unified framework. Such a framework conjectures that people evaluate all fuels in terms of a common set of attributes: affordability, environmental cleanliness, security, and so forth. People evaluate each fuel according to those attributes and use them to formulate preferences about how they would like the United States to generate electricity. Attributes have different weight in people's thinking; cost may be more important than security, for instance. Structuring energy choices in terms of attributes allows us to think of public opinion not as unique to the fuel type, but as driven by a common set of considerations.

In a series of public opinion surveys sponsored by MIT and Harvard beginning in 2002, we have examined the public's energy choice by way of two important attributes: affordability (or economic cost) and cleanliness (or environmental harm). 3
Several key findings emerge. First, people Stephen hold beliefs about the economic and en- Ansolabehere vironmental consequences for all the main $\begin{aligned} & \text { E David M. } \\ & \text { Konisky }\end{aligned}$ energy sources. Individuals do not all perceive the costs and harms of fuels accurately, but at the aggregate level, public opinion is strongly consistent with elite assessments of the relative cost and environmental harms associated with the major fuels used to generate electricity. Second, nearly all respondents in recent national surveys express a preference about whether they would like the United States to use more or less of the major fuel sources for electricity generation, including coal, natural gas, nuclear power, oil, and hydro, wind, and solar power. Third, people value both affordability and the environment. Individuals express opinions about future energy use that are based on their perceptions of costs and harms. Those who perceive a fuel as less costly and less harmful to the environment express a desire to increase use of that fuel. Importantly, this pattern holds across all fuels. Perceptions of the economics and the environmental harms strongly predict preferences about the use of each energy source.

Thinking about energy choices in this way allows us to characterize public opinion in terms of publicly acceptable alternatives. That is, we can think of energy policy as choices about different attributes of the U.S. electricity generation portfolio. Rather than conceiving of the portfolio as many unique and distinctive fuel sources, we characterize public opinion on energy according to a handful of attributes. Consider the two attributes of affordability to consumers and environmental cleanliness. We can map out how affordable and clean the public perceives each fuel source to be. Then, using the relative weight of cost and environmental harm, we can assess how the public weighs costs and harms relative to each other in evaluating 
The the trade-off between fuels that are relaAmerican tively inexpensive but environmentally
Public's Public's
Energy harmful, such as coal, and fuels that are Choice relatively expensive but environmentally less harmful, such as wind and solar power. The public's demand for one or the other of these fuels depends on how strongly costs and environmental harm are valued.

Public opinion, of course, does not mirror the marketplace. In fact, it may reflect what does not happen in the private sector. Industrial production of electricity does not fully capture the cost of environmental harms and damages. 4 Public opinion on energy expresses the relatively high value that people place on further reduction of pollution from electricity generation, beyond what is reflected in prices.

Most public opinion research on energy before 2000 was driven by specific concerns or events associated with particular forms of power generation. The gasoline price shocks, the 1969 oil spill off the coast of Santa Barbara, the accident at Three Mile Island, and other events spawned public opinion research about specific crises. ${ }^{5}$ The framework presented here builds on such research, but in a way that broadens the picture. While each of those earlier events concerned important aspects of the energy system - whether price or environmental damage - the new wave of survey research on energy attempts to measure the bases of public opinion across the range of energy choices.

A second long-standing avenue of research on the environment concerns tradeoffs. Since the 1970s, survey researchers have asked respondents what they think is more important, "jobs or the environment" (also formulated as "economic development or environment"). This question has been criticized as not being specific enough to inform policy choices, and as not presenting the right choices.
Lower energy costs are often viewed as the alternative to environmental regulation. Setting these particular concerns aside, this question attempts to establish how people will trade off one value against another. The question seeks to do explicitly what we do implicitly: that is, assess the degree to which people are willing to trade off higher cost to achieve a cleaner energy system.

Finally, survey research on global warming has greatly expanded. Resources for the Future, the Pew Center on Global Climate Change, and Yale and George Mason Universities, among others, have probed the public's willingness to adopt aggressive climate regulations. Most of this polling asks about climate change directly, and then about conservation, fuel types, and other features of energy use in the context of climate change. We flip this approach on its head, starting with what people know about energy and what it means for designing a publicly acceptable policy to address greenhouse gases.

Th he traditional framing of survey questions about energy pits jobs versus the environment. This formulation has been criticized because it oversimplifies the true choices and because it presents a tradeoff that need not always be present. Nonetheless, it does capture an essential element about energy and the American public. All fuels can be thought of as having a set of attributes, and perhaps the most important are the economics of providing electricity using that fuel and the environmental externalities produced by that process. There are other important attributes, such as the safety of the production process and national security concerns arising from the supply of different energy sources; however, most public debate and opinion research concerns the economics of providing electricity and the environmental side effects. 
A series of surveys conducted through the MIT Energy Initiative gauges how people perceive the economic costs and environmental harms associated with each type of fuel used to generate electricity in the United States today. These surveys, conducted in 2002, 2003, 2006, 2007,2009 , and 2010, were among the first to compare public perceptions of and attitudes about the major fuel sources. The surveys first ask, "How expensive or inexpensive is it to use each of the following fuel sources?" For each fuel source, respondents are provided a range of options, from "very expensive" to "very cheap." The surveys also ask: "Different ways of producing electricity cause pollution, such as air pollution, water pollution, and toxic wastes. How harmful do you think each of the following is to the environment?" Respondents are allowed to evaluate each on a scale from "very harmful" to "not harmful at all."

A fairly consistent pattern of responses emerges in all the energy surveys. On the question of environmental harm, Americans see a wide gulf between traditional and "alternative" fuels. Americans, on the whole, think that coal, oil, and nuclear power are harmful to the environment. They think that natural gas is somewhat harmful to the environment, and large majorities view solar, wind, and to a lesser degree hydro, power as not harmful at all.

On the question of economic cost, a similar gap emerges. The average American sees oil and natural gas as somewhat expensive, followed by nuclear power and then coal. Solar and wind power are viewed as somewhat inexpensive. Figure 1 shows the average value of the perceived harm and perceived cost of using each fuel source, as determined by the 2008 MIT Energy Survey. Some of the values move over the course of the last decade. Oil, for example, was perceived to be somewhat less expensive at the beginning of the decade than it was at the end, a change Stephen that reflected rising oil prices.

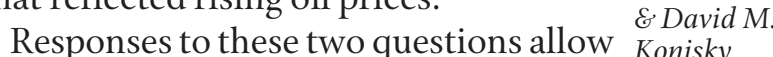
us to map out how people perceive energy choices according to certain attributes. Wind and solar, for example, are perceived to rate highly on both environmental cleanliness and economic cost. These perceptions are certainly wrong on affordability, which we consider in the final section of this paper. Among the traditional fuel sources, natural gas dominates oil: natural gas is seen as slightly less expensive than oil and somewhat less harmful to the environment. In comparison with natural gas, nuclear power is deemed as just slightly more harmful to the environment and somewhat more expensive. Coal shows an even more dramatic difference with natural gas; it is perceived as noticeably less expensive and substantially more harmful to the environment. (Natural gas is in fact a more costly but cleaner alternative to coal.)

T he MIT/Harvard Energy Surveys also ask whether the United States should increase or decrease its use of each fuel to generate electricity. A strong majority (about 75 percent) wants to increase the amount of solar and wind power in the American energy portfolio, while majorities also desire reduced reliance on coal and oil. These broad assessments are consistent with the findings shown in Figure 1, but there is a deeper question: which attribute is more important in explaining preferences? How an elected official or regulator might make decisions that are responsive to public opinion depends not just on how the public perceives different attributes, but on how much weight these attributes have. The relative importance of environment and economics in public thinking can guide how we as a society choose between less expensive but environmentally more harmful fuels and more 
The Figure 1

American Perceived Harm and Perceived Price of Energy Sources as Related to Desired Future Use Public's

Energy

Choice
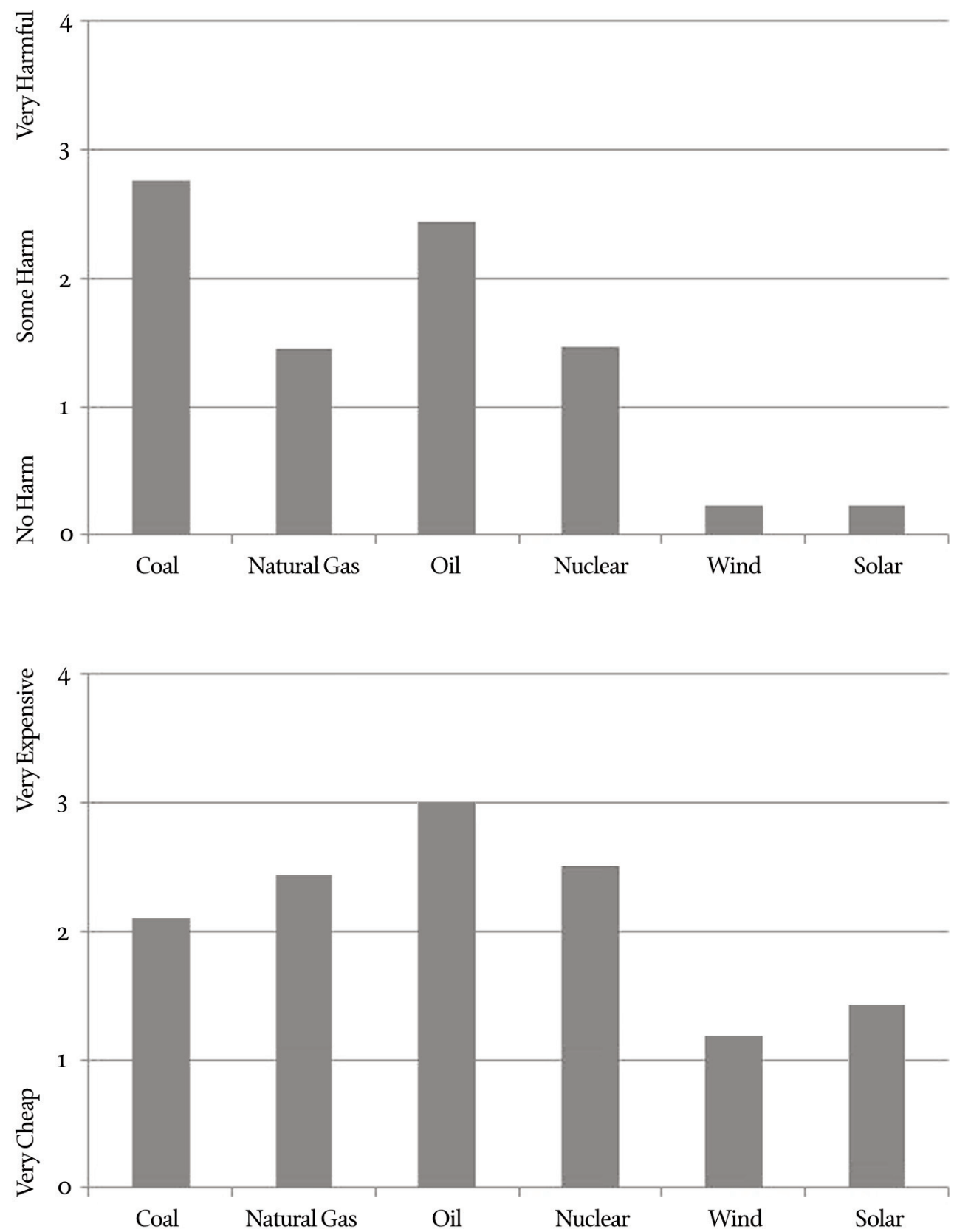

Bars represent mean value for each energy source. Source: Energy Survey 2008, MIT/Harvard Energy Surveys. 
expensive but environmentally less harmful fuels. In short, how do we decide between coal and natural gas, and, eventually, between fossil fuels and renewable sources?

One can measure the relative weight of attributes in two ways. First, we use perceptions of harm and cost to predict individuals' expressed preferences about whether they think the country should use more or less of each fuel type. We make this prediction by regressing expressed preferences about fuel use on perceived cost, perceived environmental harm, and other factors. Second, we conduct experiments in which some survey respondents are told the actual prices of producing electricity from each source. We can then measure the magnitude of the difference in preferences about which energy source to use between those who are given the correct price information and those who are not. Of particular interest is whether the public becomes less enthusiastic about renewable sources upon learning the relatively high price of those alternatives, and whether the change in preferences is consistent with the first sort of analysis.

Figure 2 shows the relative weight of perceived economic costs and perceived environmental harms associated with each fuel in survey respondents' evaluations of whether the United States should use more or less of a given fuel. ${ }^{6}$ The graph shows standardized regression coefficients and their associated 95 percent confidence interval for each perception. In this graph, positive values mean that a given attribute (environmental cleanliness or economic affordability) is valued more highly. ${ }^{7}$

Several qualitative findings stand out. First, Americans value the environment more than affordability. Environmental considerations have a stronger effect than economic considerations in predicting whether people want to increase or decrease use of a given fuel. The difference Stephen is particularly large for coal and nuclear Ansolabehere power, but it holds for each fuel source.

Second, the weight given to cost is similar (and statistically indistinguishable) across the fuel types. Prices have approximately the same effect on people's thinking about energy use regardless of the fuel. This is an important finding, as it indicates that people respond to prices of each fuel source in the same way. In accord with economic intuitions, people want to substitute more expensive fuels with cheaper fuels regardless of what fuels are involved.

Third, the weights of perceived environmental harms are about the same for most fuels. The weights are indistinguishable for natural gas, oil, solar, and wind. Environmental harms have much greater weight when people think about coal and nuclear power. Considering that coal is seen as the most harmful for the environment, these data suggest a very strong willingness among the American public to move away from coal, even though it is cheaper than alternative fuels.

Fourth, these results reveal that people think about all fuels through a common lens. The weights of perceived prices are approximately the same in public assessments of all fuels, and the weights of perceived environmental harms are approximately the same for natural gas, oil, wind, and solar power. This finding is somewhat surprising because solar and wind are often talked about separately from gas and oil - as if renewable technologies differ fundamentally from fossil fuels. Instead, we find that people think about these fuels using the same attributes and in the same ways, though they have different perceptions of those attributes. Coal and nuclear power differ from the other fuels in the environmental domain; people weigh environmental considerations much more when they think about whether to use 
The Figure 2 American
Public's

Energy

Choice

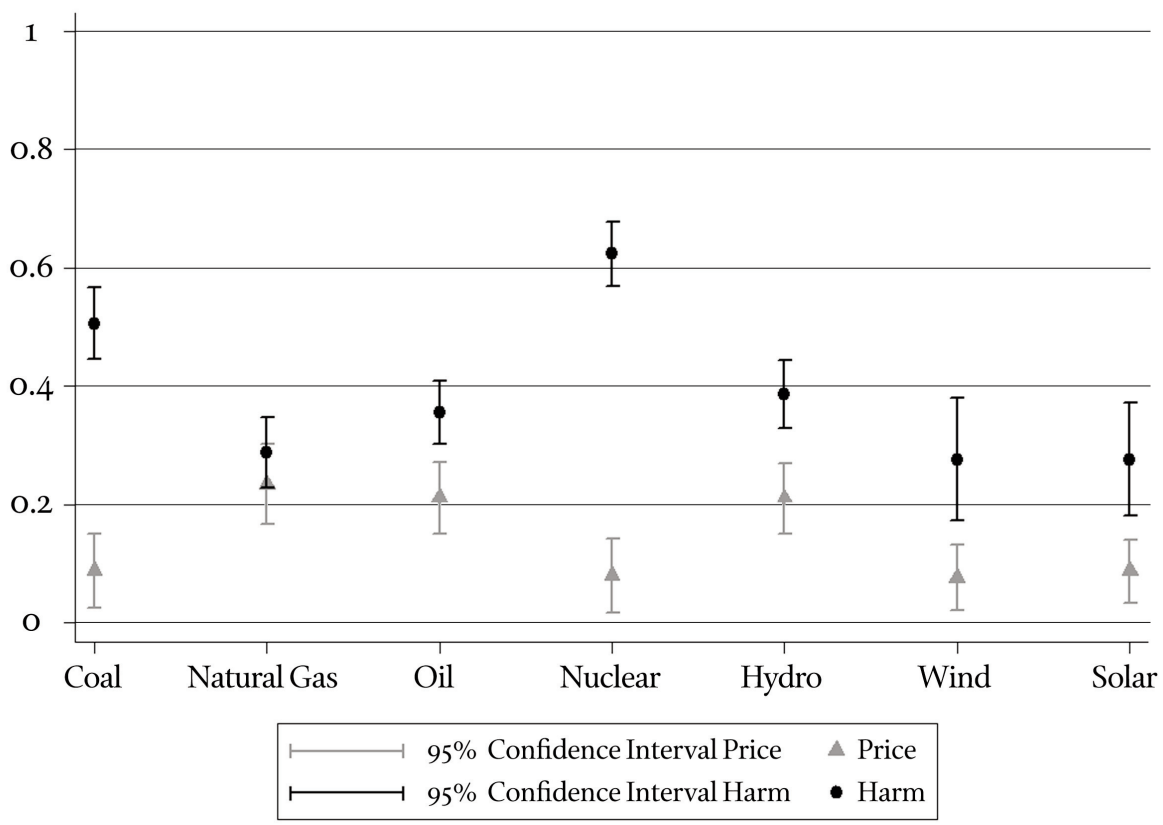

Source: Energy Survey 2008, MIT/Harvard Energy Surveys.

more of those fuels. This is a serious liability for coal, suggesting that public support for increasing its use is highly dependent on making it into a cleaner fuel (which is quite expensive to do).

A final question is whether people think of environmental harm in local or global terms. The question analyzed so far framed environmental harm in local terms. The surveys also ask respondents how concerned they are about global warming and how willing they are to pay to reduce global warming. In the 2002 MIT Energy Survey, the weight of the measure of concern about global warming was statistically indistinguishable from zero in most of our analyses predicting preferences about future use of fuel source. Only for wind and solar power did concern about global warming matter for people's thinking about the fuel, and even then the effect was small. By the end of the decade, the importance of global warming in thinking about energy had risen, but the effect was still much smaller than the effects of either local pollution or energy prices. Attitudes about global warming have weak or no correlation with attitudes about which fuels we use to generate electricity in the United States. The environmental concerns that people rely on in thinking about energy production and policy, then, are local environmental and health considerations, not global ones.

Experiments provide another way to measure the sensitivity of future energy preferences to perceptions of price and environmental harm. The 2002 MIT Energy Survey included an experiment to measure shifts in attitudes for different energy sources in light of information 
about changes in costs and harms. The survey sample was randomly divided into five groups. Three groups were provided information about 1) current prices of power generation and projected increases in the costs of fossil fuels relative to other energy sources over the next twenty-five years; 2) current prices of power generation and global warming threats from burning fossil fuels; or 3) current prices of power generation and toxic wastes generated as a by-product of burning fossil fuels. A fourth group was provided all three messages, and a fifth group, serving as a control, was provided with no information. Each group was then asked whether the United States should increase or decrease the use of each energy source of generating electricity.

The effects of the information were modest; that is, people's preferences for increasing or decreasing the use of a particular fuel did not differ much for groups receiving the various messages compared to the group that did not receive any information. One notable exception pertains to the price information. Compared to the control group, individuals provided information about the price of energy were more likely to support the increased use of coal, oil, and nuclear power and more likely to support the reduced use of wind, solar, and hydro power. These differences were each statistically significant, except for the case of nuclear power. In other words, upon being provided factual information about the relative costs of energy sources, support for traditional fuels increased, while support for the increased use of renewable technologies diminished. There was no similar difference for the groups provided information about global warming or toxic waste; these messages did little to affect preferences for either fossil fuels or renewables. The one deviation from this pattern is that, when provided information about price and environmental harm (particularly Stephen toxic wastes), respondents on average were Ansolabehere more likely to favor increased use of nu- \& David M.

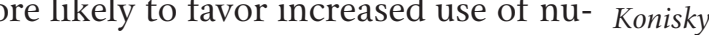
clear power compared to respondents receiving no information. These experimental results show that, similar to the regression analysis, people do not connect global warming to future policies about electricity production.

Additional experiments administered in the 2007 and 2008 MIT Energy Surveys replicated the findings on cost. When informed that solar and wind power are much more expensive than coal and natural gas, support for coal and natural gas rose slightly, and support for solar and wind power dropped substantially.

$\mathrm{Pu}$ the United States points repeatedly to one unfortunate conclusion: concern about global warming is, at best, weakly correlated with attitudes toward particular fuels. That weak correlation suggests that raising the alarm and public education about global warming are unlikely to lead to radical changes in public opinion about energy production and use.

The analyses described above reveal that even if all Americans thought climate change required immediate action, support for coal would decline by only 0.10 on a scale from zero to one, support for solar and wind power would increase by only 0.20 , and support for nuclear power would actually decline. That result is consistent with a separate literature on Americans' willingness to pay to reduce greenhouse gas emissions, as well as their support for climate change legislation and international climate agreements. With the exception of recent work by social psychologist Jon Krosnick of Stanford University, ${ }^{8}$ nearly all survey research in this area shows that people are willing to approve of only modest carbon taxes or regulatory changes in order to slow green- 
The house gas emissions. Climate change, American
Public's Energy officials, policy pundits, and environmen-

Choice tal advocates, is clearly not going to drive public opinion about energy use and energy policy.

But there is another way to take on the climate problem. The results here reveal that the public is willing to support changes in the mix of fuels used to generate electricity when those changes are based on local environmental problems. Recent analyses by economist Michael Greenstone of MIT and Adam Looney, a senior fellow in economic studies at the Brookings Institution, indicate that much of the increase in the price of coal needed to reduce use of that fuel can be accomplished through stricter regulation of local pollution problems, such as emissions of ozone precursors, particulates, and mercury. 9

Regulations that tackle these problems will help make a first cut at greenhouse gas emissions from electricity for the simple reason that those problems arise disproportionately with the use of coal. Such a regulatory approach is not a climate policy per se, because it would not regulate coal for the explicit purpose of decreasing carbon emissions. However, regulations aimed at improving local air quality by reducing emissions from coal combustion would have the effect of also reducing greenhouse gas emissions by reducing the use of coal in general. And regulation of pollution from coal-fired power plants would likely receive substantially more public support than similar efforts to reduce coal use through regulation of greenhouse gas emissions.

Perhaps the most intriguing finding is the unity that we see across fuels. For decades, survey research has treated opinion about different power sources as unique. The new wave of survey research suggests that people view all fuels through the same lens. Technological advances that diminish environmental harm or reduce costs will make fuel sources more competitive in the economic marketplace, more acceptable to the public, and more palatable in the political realm.

\section{ENDNOTES}

* Contributor Biographies: STEPHEN AnsolabeHERE, a Fellow of the American Academy since 2007, is Professor of Government at Harvard University. His publications include The End of Inequality: One Person, One Vote, and the Transformation of American Politics (with James M. Snyder, Jr., 2008), Going Negative: How Attack Ads Shrink and Polarize the Electorate (with Shanto Iyengar, 1995), and The Media Game: American Politics in the Television Age (with Roy Behr and Shanto Iyengar, 1993).

DAVID M. KONISKY is an Assistant Professor at the Georgetown Public Policy Institute. He is a coauthor of the book Superfund's Future: What Will It Cost? (2001). His research has been published in such journals as the Political Research Quarterly, State Politics and Policy Quarterly, Public Opinion Quarterly, and American Journal of Political Science.

1 See, for example, The Future of Nuclear Power: An Interdisciplinary MIT Study (Cambridge, Mass. : Massachusetts Institute of Technology, 2003; updated 2009); The Future of Coal: An Interdisciplinary MIT Study (Cambridge, Mass.: Massachusetts Institute of Technology, 2007); Toby Bolsen and Fay Lomax Cook, "The Polls - Trends : Public Opinion on Energy Policy: 1974-2006," Public Opinion Quarterly 72 (2) (2008):364-388; and Eric R.A.N. Smith, Energy, the Environment, and Public Opinion (Lanham, Md.: Rowman \& Littlefield, 2002).

2 There has been some effort to understand how Americans weigh energy development and environmental protection, specifically with regard to strip-mining for coal, offshore drilling 
for oil and gas, and the opening of the Arctic National Wildlife Refuge to gas and oil explo- Stephen ration.

3 The The surveys were administered through the Internet by Knowledge Networks to a national- Konisky ly representative group of adult respondents. Knowledge Networks recruits and maintains a panel of individuals who participate in client-based surveys, such as our surveys of energy attitudes.

4 For a comprehensive report, see National Research Council, Hidden Costs of Energy (Washington, D.C.: National Academies Press, 2010).

5 Paul Slovic, among others, saw a broader framework in which to understand opinion about nuclear power. For more on his risk framework, see Paul Slovic, "Perceptions of Risk," Science 236 (1987): $280-285$.

6 The regression also includes control variables for various demographic characteristics (age, education, income, race or ethnicity, gender, and marital status), political attitudes, and region of residence. For a similar analysis in the context of not-in-my-backyard (NIMBY) attitudes about different types of power plants, see Stephen Ansolabehere and David M. Konisky, "Public Attitudes toward Construction of New Power Plants," Public Opinion Quarterly 73 (3) (2009): $566-577$.

7 Standardized regression coefficients allow for more direct comparison of the measures used. One can interpret the expected change in the dependent variable for each standard deviation increase in the measure of interest.

8 Jon Krosnick, "Large Majority of Americans Support Government Solutions to Address Global Warming," Woods Institute for the Environment, Stanford University, June 2010, http:// woods.stanford.edu/research/americans-support-govt-solutions-global-warming.html.

9 Michael Greenstone and Adam Looney, “A Strategy for America’s Energy Future: Illuminating Energy's Full Costs,” The Hamilton Project (Washington, D.C.: Brookings Institution, 2011). 